\title{
BMJ
}

\section{Kidney function and risk of cardiovascular disease and mortality in women: a prospective cohort study}

\author{
Tobias Kurth, senior researcher, ${ }^{1,2,3,4}$ Paul E de Jong, professor, ${ }^{5}$ Nancy R Cook, associate professor, ${ }^{1,2}$ Julie E \\ Buring, professor, ${ }^{1,2,6,7,8}$ Paul M Ridker, professor ${ }^{1,2,5,6}$
}

${ }^{1}$ Division of Preventive Medicine, Department of Medicine, Brigham and Women's Hospital, Harvard Medical School, Boston MA, USA ${ }^{2}$ Department of Epidemiology, Harvard School of Public Health, Boston MA

${ }^{3}$ INSERM Unit 708-

Neuroepidemiology, Paris, France

${ }^{4}$ Faculty of Medicine, University Pierre et Marie Curie, Paris, France

${ }^{5}$ Department of Internal Medicine, University Medical Center Groningen, Groningen, the

Netherlands

${ }^{6}$ Center for Cardiovascular Disease Prevention, Department of Medicine, Brigham and Women's Hospital

\section{${ }^{7}$ Donald W Reynolds Center for} Cardiovascular Research,

Department of Medicine, Brigham and Women's Hospital

${ }^{8}$ Department of Ambulatory Care and Prevention, Harvard Medical School

Correspondence to: T Kurth, INSERM Unit 708Neuroepidemiology, Hôpital de la Pitié-Salpêtrière, 47 boulevard de l'Hôpital, 75651 Paris Cedex 13, France

tkurth@rics.bwh.harvard.edu

Cite this as: BMJ 2009;338:b2392 doi:10.1136/bmj.b2392

\section{ABSTRACT}

Objective To evaluate the association of kidney function with cardiovascular disease and mortality among apparently healthy women.

Design Prospective cohort study.

Setting Women's Health Study, United States.

Participants 27939 female health professionals aged $\geq 45$ who were free of cardiovascular disease and other major disease and who provided a blood sample at study entry.

Main outcome measures Time to cardiovascular disease (non-fatal stroke, non-fatal myocardial infarction, coronary revascularisation procedures, or death from cardiovascular cause), specific cardiovascular disease events, and all-cause mortality. End points were confirmed after review of medical records and death certificates.

Results Glomerular filtration rate (GFR) was estimated with the abbreviated Modification of Diet in Renal Disease Study equation. At baseline, 1315 (4.7\%) women had GFR $<60 \mathrm{ml} / \mathrm{min} / 1.73 \mathrm{~m}^{2}$. During 12 years of follow-up, 1199 incident cardiovascular disease events and 856 deaths (179 from cardiovascular disease) occurred. Compared with women with GFR $\geq 90 \mathrm{ml} / \mathrm{min} / 1.73 \mathrm{~m}^{2}$, the multivariable adjusted hazard ratios for any first cardiovascular disease were 0.95 ( $95 \% \mathrm{Cl} 0.83$ to 1.08), 0.84 ( 0.70 to 1.00 ), and 1.00 (0.79 to 1.27 ) among women with GFR of $75-89.9,60-74.9$, and $<60 \mathrm{ml} / \mathrm{min} /$ $1.73 \mathrm{~m}^{2}$, respectively; the equivalent hazard ratios for all cause mortality were 0.93 (0.79 to 1.09), 1.03 (0.85 to 1.26 ), and 1.09 (0.83 to 1.45$)$. Similar null findings were observed for myocardial infarction, stroke, coronary revascularisation, and non-cardiovascular death. However, an increased risk of death from cardiovascular disease was found among women with GFR $<60 \mathrm{ml} / \mathrm{min}$ / $1.73 \mathrm{~m}^{2}$ (hazard ratio 1.68 (1.02 to 2.79 )).

Conclusions In this large cohort of women, a glomerular filtration rate $<60 \mathrm{ml} / \mathrm{min} / 1.73 \mathrm{~m}^{2}$ was associated with increased risk of cardiovascular disease death but not other cardiovascular disease events or noncardiovascular disease mortality. We observed no increase in risk of any of the outcomes among women with less severe impairment of kidney function.

Chronic kidney disease and cardiovascular disease are emerging public health problems in the United States and worldwide, ${ }^{12}$ and these two diseases seem to have a complex relation. ${ }^{3-5}$ For example, the prevalence of traditional risk factors for cardiovascular disease is increased in patients with impaired kidney function, ${ }^{4}$ and these risk factors predict the start of chronic kidney disease. ${ }^{6-9}$ Furthermore, several studies suggest an association between impaired kidney function and cardiovascular disease as well as mortality from all causes $^{10-15}$ and specifically from cardiovascular disease. ${ }^{16}$ Most studies of the association between kidney function and cardiovascular disease or mortality have been limited to individuals at high risk for cardiovascular disease, with existing cardiovascular disease, or with severely impaired kidney function.

However, studies of the association between impaired kidney function and cardiovascular disease among people not selected on the basis of cardiovascular risk or impaired kidney function showed less consistent results. ${ }^{16-19} \mathrm{We}$ therefore evaluated the association between kidney function and cardiovascular disease as well as mortality in the prospective Women's Health Study among more than 27939 women who were at least 45 years old and did not have cardiovascular disease or other major disease, including symptomatic kidney disease, at study entry.

\section{METHODS}

Study population

We conducted a prospective cohort study among participants in the Women's Health Study, a completed randomised placebo controlled trial designed to test the benefits and risks of low dose aspirin and vitamin $\mathrm{E}$ in the primary prevention of cardiovascular disease and cancer. The study's design, methods, and results have been described in detail previously. ${ }^{20-22}$ Briefly, a total of 39876 US female health professionals aged $\geq 45$ years at study entry (1992-5), who were mostly white $(94 \%)$, and without a history of cardiovascular disease, cancer, or other major illnesses were randomly assigned to aspirin (100 $\mathrm{mg}$ on alternate days), vitamin E (600 IU on alternate days), both active agents, or both placebos. All participants provided written informed consent and the Institutional Review Board of Brigham and Women's Hospital (Boston MA, USA) approved the study. Baseline information was self 
reported and collected by a mailed questionnaire that asked about many cardiovascular risk factors and lifestyle variables.

\section{Blood measurements}

Blood samples were collected from 28345 participants before randomisation. Of those, 406 samples could not be analysed because of technical limitations, leaving 27939 participants for analysis. All blood samples were collected in tubes containing EDTA and stored in vapour phase liquid nitrogen $\left(-170^{\circ} \mathrm{C}\right)$. In a core laboratory certified by the National Heart, Lung, and Blood Institute-Centers for Disease Control and Prevention Lipid Standardisation Program, samples were analysed for lipids and a panel of inflammatory biomarkers. Creatinine was measured by a rate blanked method that is based on the Jaffé reaction. Total cholesterol was assayed with reagents from Roche Diagnostics (Basel, Switzerland) and high sensitivity $\mathrm{C}$ reactive protein concentrations were measured with immunoturbidimetric assays on a Hitachi 917 analyser (Roche Diagnostics, Indianapolis, USA) using reagents and calibrators from Denka Seiken (Tokyo, Japan).

\section{Kidney function}

As the primary measure of kidney function, we estimated glomerular filtration rate (GFR) by the abbreviated prediction equation developed from the Modification of Diet in Renal Disease Study, ${ }^{23}$ as recommended by the National Kidney Foundation ${ }^{24}$ :

Estimated GFR (in $\left.\mathrm{ml} / \mathrm{min} / 1.73 \mathrm{~m}^{2}\right)=186 \times[$ serum creatinine $(\text { in } \mathrm{mg} / \mathrm{dl})^{-1.154} \times \mathrm{Age}^{-0.203} \times 0.742($ female $)$ $\times 1.210$ (if black)]

We categorised participants based on their estimated GFR as <60, 60-74.9, 75-84.0, and $\geq 90 \mathrm{ml} / \mathrm{min} /$ $1.73 \mathrm{~m}^{2}$, based on the classification of the National Kidney Foundation. ${ }^{24}$ In sensitivity analyses, we also evaluated categories of GFR of $<40 \mathrm{ml} / \mathrm{min} / 1.73 \mathrm{~m}^{2}$ with risks of cardiovascular disease. We had too few participants in lower categories of GFR to perform meaningful analyses.

As a secondary measure for kidney function, we used plasma creatinine concentration, which we categorised according to the following centile cut-offs: $<50$ th $(\leq 0.71 \mathrm{mg} / \mathrm{dl}, \leq 63 \mu \mathrm{mol} / \mathrm{l}), 50-74$ th $(0.72$ $0.79 \mathrm{mg} / \mathrm{dl}, 64-70 \mu \mathrm{mol} / \mathrm{l}), 75-94$ th $(0.80-1.00 \mathrm{mg} / \mathrm{dl}$, $71-88 \mu \mathrm{mol} / \mathrm{l})$, and $\geq 95 \mathrm{th}(\geq 1.01 \mathrm{mg} / \mathrm{dl}, \geq 89 \mu \mathrm{mol} / \mathrm{l})$.

\section{Outcome ascertainment}

During follow-up, participants self reported cardiovascular events and coronary revascularisations. Medical records were obtained for all these events and reviewed by an endpoints committee of physicians. The occurrence of myocardial infarction was confirmed if symptoms met World Health Organization criteria and if the event was associated with abnormal levels of cardiac enzymes or diagnostic electrocardiograms. Non-fatal stroke was confirmed if the participant had a new focal-neurological deficit of sudden or rapid onset that persisted for $>24$ hours and attributed to a cerebrovascular event, and was classified into its major subtypes based on available clinical and diagnostic information with excellent interobserver agreement. ${ }^{25}$ Deaths were confirmed by review of autopsy reports, death certificates, medical records, or information obtained from next of kin or family members and classified according to its cause.

The primary outcome was any first cardiovascular event, a combined end point defined as the first of any of these events: non-fatal stroke, non-fatal myocardial infarction, coronary revascularisation procedures, or death from cardiovascular disease. We also evaluated the association between kidney function with any first individual cardiovascular event, allcause mortality, and non-cardiovascular mortality.

\section{Statistical analyses}

We compared baseline characteristics of participants according to GFR categories. To compare mean response among the categories, we used analyses of covariance adjusting for age. We used direct standardisation to adjust categorical variables and incidence rates for cardiovascular disease for age in 5-year increments.

We used Cox proportional hazards models to evaluate the association of GFR and plasma creatinine categories with the various outcomes. We calculated hazard ratios adjusted for age and for multiple variables and their 95\% confidence intervals. The multivariable models controlled for age (continuous), systolic blood pressure categories $(10 \mathrm{~mm} \mathrm{Hg}$ increments), antihypertensive treatment (yes, no), smoking (never, past, current), body mass index $(<25,25-29.9$, $\geq 30 \mathrm{~kg} / \mathrm{m}^{2}$ ), alcohol consumption (rarely/never, $<1$ drink/week, 1-6 drinks/week, $\geq 1$ drinks/day), exercise (rarely/never, $<1$ time/week, 1-3 times/week, $\geq 4$ times/week), total cholesterol concentration (quartiles), C reactive protein concentration (quartiles), postmenopausal hormone use (never, past, current), history of diabetes (yes, no), as well as randomised treatment assignments. We incorporated a missing value indicator to the multivariable models if the number of women with missing information on covariates was $>100$ or assigned missing information to the reference or the past user category, if applicable.

We tested the proportionality assumption by including an interaction term for GFR category with person time in the Cox models and found no statistically significant violation.

We evaluated whether the association between GFR and any cardiovascular disease or all-cause mortality was modified by age $(<55,55-64, \geq 65$ years $)$, body mass index $\left(<25,25-<30\right.$, and $\left.\geq 30 \mathrm{~kg} / \mathrm{m}^{2}\right)$, history of hypertension (systolic blood pressure $\geq 140 \mathrm{mmHg}$, diastolic blood pressure $\geq 90 \mathrm{~mm} \mathrm{Hg}$, or use of antihypertensive drugs), smoking status (never, past, current), $\mathrm{C}$ reactive protein $(<10,10-29, \geq 30 \mathrm{mg} / \mathrm{l})$ and total cholesterol concentration $(<5.18,5.18-6.19$, $\geq 6.22 \mathrm{mmol} / \mathrm{l})$. We checked for significant effect modification by adding appropriate indicator variables to 
the models and compared nested models by using $\chi^{2}$ statistics. We calculated $\mathrm{P}$ for trend across median values of the glomerular filtration rate and creatinine categories. All analyses were performed with SAS version 9.1 (SAS, Cary, NC); All P values were two tailed, and a $\mathrm{P}$ value $<0.05$ was considered statistically significant.

\section{RESULTS}

Of the 27939 participating women, $14979(53.6 \%)$ had a GFR $\geq 90 \mathrm{ml} / \mathrm{min} / 1.73 \mathrm{~m}^{2}, 8073(28.9 \%)$ had a GFR of $75-89 \mathrm{ml} / \mathrm{min} / 1.73 \mathrm{~m}^{2}, 3572(12.8 \%)$ had a GFR of $60-74 \mathrm{ml} / \mathrm{min} / 1.73 \mathrm{~m}^{2}$, and $1315(4.7 \%)$ had a GFR $<60 \mathrm{ml} / \mathrm{min} / 1.73 \mathrm{~m}^{2}$. Table 1 shows the association between baseline characteristics and GFR categories. Compared with women with a GFR $\geq 90 \mathrm{ml} / \mathrm{min} /$ $1.73 \mathrm{~m}^{2}$, women with a rate $<60 \mathrm{ml} / \mathrm{min} / 1.73 \mathrm{~m}^{2}$ were older, had higher total cholesterol and $\mathrm{C}$ reactive protein values, and were more likely to be

Table 1| Age adjusted baseline characteristics of 27939 participants in the Women's Health Study by estimated glomerular filtration rate. ${ }^{\star}$ Values are percentages of participants unless stated otherwise

\begin{tabular}{|c|c|c|c|c|}
\hline \multirow[b]{2}{*}{ Characteristics } & \multicolumn{4}{|c|}{ Glomerular filtration rate $\left(\mathrm{ml} / \mathrm{min} / 1.73 \mathrm{~m}^{2}\right)$} \\
\hline & $<60(n=1315)$ & $60-74(n=3572)$ & $75-89(n=8073)$ & $\geq 90(n=14979)$ \\
\hline Mean (SE) age (years) & $57.1(0.22)$ & $56.5(0.13)$ & $55.2(0.08)$ & $53.8(0.05)$ \\
\hline $\begin{array}{l}\text { Mean (SE) total cholesterol } \\
\text { concentration }(\mathrm{mmol} / \mathrm{l})\end{array}$ & $6.59(0.03)$ & $5.82(0.02)$ & $5.50(0.01)$ & $5.29(0.01)$ \\
\hline $\begin{array}{l}\text { Mean }(\mathrm{SE}) \mathrm{C} \text { reactive protein } \\
\text { concentration }(\mathrm{mg} / \mathrm{l})\end{array}$ & $4.2(0.16)$ & $3.5(0.1)$ & $3.4(0.06)$ & $3.8(0.05)$ \\
\hline $\begin{array}{l}\text { Mean (SE) body mass index } \\
\left(\mathrm{kg} / \mathrm{m}^{2}\right)\end{array}$ & $26.0(0.14)$ & $25.9(0.08)$ & $25.8(0.06)$ & $26.0(0.04)$ \\
\hline Body mass index $\geq 30 \mathrm{~kg} / \mathrm{m}^{2}$ & 18.8 & 17.1 & 16.6 & 18.3 \\
\hline $\begin{array}{l}\text { Mean (SE) systolic blood } \\
\text { pressure }(\mathrm{mm} \mathrm{Hg})\end{array}$ & $123.9(0.37)$ & $123.2(0.22)$ & $123.2(0.15)$ & $124.1(0.11)$ \\
\hline Hypertension & 27.4 & 25.0 & 23.7 & 25.6 \\
\hline Antihypertensive treatment & 16.6 & 14.0 & 12.4 & 13.4 \\
\hline Diabetes & 2.4 & 2.1 & 2.1 & 2.7 \\
\hline \multicolumn{5}{|l|}{ Smoking status: } \\
\hline Never & 51.3 & 51.9 & 52.8 & 51.0 \\
\hline Past & 37.6 & 36.7 & 36.4 & 36.7 \\
\hline Current & 11.1 & 11.5 & 10.8 & 12.3 \\
\hline \multicolumn{5}{|l|}{ Alcohol consumption: } \\
\hline Rarely/never & 42.7 & 43.8 & 42.2 & 45.3 \\
\hline «1 drink/week & 13.1 & 13.1 & 13.3 & 13.4 \\
\hline 1-6 drinks/week & 34.4 & 33.2 & 33.6 & 31.1 \\
\hline$\geq 1$ drinks/day & 9.7 & 9.9 & 10.9 & 10.3 \\
\hline \multicolumn{5}{|l|}{ Physical activity: } \\
\hline Rarely/never & 34.9 & 36.7 & 35.4 & 38.5 \\
\hline «1 time/week & 18.5 & 18.5 & 19.0 & 20.1 \\
\hline 2-3 times/week & 33.1 & 32.6 & 33.7 & 30.7 \\
\hline$\geq 4$ times/week & 13.6 & 12.2 & 12.0 & 10.7 \\
\hline \multicolumn{5}{|l|}{$\begin{array}{l}\text { Postmenopausal hormone } \\
\text { use: }\end{array}$} \\
\hline Never & 47.6 & 48.2 & 49.8 & 47.9 \\
\hline Past & 9.3 & 9.6 & 8.9 & 8.7 \\
\hline Current & 43.1 & 42.2 & 41.3 & 43.5 \\
\hline Randomised to aspirin use & 49.4 & 49.8 & 50.7 & 49.8 \\
\hline
\end{tabular}

*Estimated with the Modification of Diet in Renal Disease Study equation. ${ }^{23}$

Proportions may not add up to $100 \%$ because of rounding and missing values.

$\mathrm{SE}=$ standard error. hypertensive and to use antihypertensive drugs, be past smokers, and be more physically active.

During a mean of 12 years of follow-up (339 303 person years), 1199 participants had at least one incident cardiovascular event (non-fatal stroke, non-fatal myocardial infarction, coronary revascularisation procedure, or death from a cardiovascular cause) and 856 women died, with 179 of the deaths caused by cardiovascular disease. We found no association between GFR categories and risk of any cardiovascular event or death from any cause. Compared with women with $\mathrm{GFR} \geq 90 \mathrm{ml} / \mathrm{min} / 1.73 \mathrm{~m}^{2}$, the multivariable adjusted hazard ratios for any first cardiovascular disease event were 0.95 (95\% confidence interval 0.83 to $1.08), 0.84$ (0.70 to 1.00$)$, and 1.00 (0.79 to 1.27 ) among women with GFR of 75-89.9, 60-74.9, and $<60 \mathrm{ml} /$ $\min / 1.73 \mathrm{~m}^{2}$ respectively; and for all-cause mortality the hazard ratios were 0.93 (0.79 to 1.09$), 1.03$ (0.85 to $1.26)$, and 1.09 (0.83 to 1.45$)$ respectively. We further found no association between GFR and myocardial infarction, coronary revascularisation procedures, stroke, or non-cardiovascular death. Comparing women with a GFR $<60 \mathrm{ml} / \mathrm{min} / 1.73 \mathrm{~m}^{2}$ with women with a rate of $\geq 90 \mathrm{ml} / \mathrm{min} / 1.73 \mathrm{~m}^{2}$, the multivariable adjusted hazard ratios were 1.03 (0.79 to 1.33 ) for myocardial infarction, 0.83 (0.59 to 1.17) for coronary revascularisation procedures, 1.03 (0.70 to 1.53) for stroke, and 0.92 (0.65 to 1.29$)$ for non-cardiovascular death (table 2). With regard to stroke subtypes, our data indicated no increased risk for the ischaemic or haemorrhagic stroke subtype: compared with women with a GFR $\geq 90 \mathrm{ml} / \mathrm{min} / 1.73 \mathrm{~m}^{2}$, women with a rate $<60 \mathrm{ml} / \mathrm{min} / 1.73 \mathrm{~m}^{2}$ had adjusted hazard ratios of 1.11 (0.73 to 1.69$)$ for ischaemic stroke and 0.66 (0.20 to 2.19) for haemorrhagic stroke.

We found a significantly increased risk of cardiovascular death (hazard ratio 1.68 (1.02 to 2.79)) for women with a GFR $<60 \mathrm{ml} / \mathrm{min} / 1.73 \mathrm{~m}^{2}$ compared with women with a GFR $\geq 90 \mathrm{ml} / \mathrm{min} / 1.73 \mathrm{~m}^{2}$. However, this increased risk was limited to women in the low GFR group, and we found no significant linear trend across GFR categories (table 2).

When we further subcategorised the low GFR group to $<40 \mathrm{ml} / \mathrm{min} / 1.73 \mathrm{~m}^{2}$, we found increased risk of death from any cause (hazard ratio 2.26 (1.15 to 4.41)) for the 67 women in that category, which was driven by increased risk of death from cardiovascular disease $(3.06$ (0.94 to 9.94$)$ ), when compared with the high GFR group. In contrast, there was no significant association with other cardiovascular disease end points with the highest point estimate for stroke (hazard ratio 1.31 (0.41 to 4.13$)$ ).

Table 3 summarises the association between categories of creatinine concentration and risk of the various outcomes. Overall, the pattern of association was similar to that found with the GFR categories. Compared with women with a creatinine concentration below the 50th centile, women with concentrations $\geq 95$ th centile had multivariable adjusted hazard ratios of 0.99 (0.78 to 1.26$)$ for any cardiovascular disease, $0.86(0.51$ to 1.43$)$ for myocardial infarction, 0.82 
Table 2| Hazard ratios (95\% confidence intervals) for cardiovascular events and mortality among 27939 participants in the Women's Health Study by estimated glomerular filtration rate.* Hazard ratios are adjusted for age and for multiple variables $\uparrow$

\begin{tabular}{|c|c|c|c|c|c|}
\hline \multirow[b]{2}{*}{ Event } & \multicolumn{4}{|c|}{ Glomerular filtration rate $\left(\mathrm{ml} / \mathrm{min} / 1.73 \mathrm{~m}^{2}\right)$} & \multirow[b]{2}{*}{$P$ value for trend $\ddagger$} \\
\hline & $<60(n=1315)$ & $60-74(n=3572)$ & $75-89(n=8073)$ & $\geq 90(n=14979)$ & \\
\hline $\begin{array}{l}\text { Any cardiovascular event } \\
(n=1199) \S:\end{array}$ & $(n=84)$ & $(n=165)$ & $(n=347)$ & $(n=603)$ & \\
\hline Age adjusted & $1.13(0.90$ to 1.42$)$ & $0.86(0.73$ to 1.03$)$ & $0.93(0.81$ to 1.06$)$ & 1.00 & 0.53 \\
\hline Multiple adjusted & $1.00(0.79$ to 1.27$)$ & $0.84(0.70$ to 1.00$)$ & 0.95 (0.83 to 1.08$)$ & 1.00 & 0.22 \\
\hline Myocardial infarction $(n=313)$ : & $(n=17)$ & $(n=50)$ & $(n=94)$ & $(n=152)$ & \\
\hline Age adjusted & $0.91(0.55$ to 1.50$)$ & $1.04(0.75$ to 1.43$)$ & $1.00(0.77$ to 1.29$)$ & 1.00 & 0.91 \\
\hline Multiple adjusted & 1.03 (0.79 to 1.33$)$ & $0.99(0.71$ to 1.37$)$ & $0.80(0.48$ to 1.34$)$ & 1.00 & 0.63 \\
\hline $\begin{array}{l}\text { Coronary revascularisation } \\
(n=675) \rrbracket:\end{array}$ & $(n=39)$ & $(n=90)$ & $(n=197)$ & $(n=349)$ & \\
\hline Age adjusted & $0.96(0.69$ to 1.33$)$ & 0.86 (0.68 to 1.08$)$ & $0.93(0.78$ to 1.11$)$ & 1.00 & 0.27 \\
\hline Multiple adjusted & $0.83(0.59$ to 1.17$)$ & 0.81 (0.64 to 1.02$)$ & $0.95(0.80$ to 1.14$)$ & 1.00 & 0.08 \\
\hline Stroke $(n=389)$ : & $(n=31)$ & $(n=50)$ & $(n=111)$ & $(n=197)$ & \\
\hline Age adjusted & $1.20(0.82$ to 1.77$)$ & $0.76(0.55$ to 1.04$)$ & $0.88(0.70$ to 1.12$)$ & 1.00 & 0.52 \\
\hline Multiple adjusted & 1.03 (0.70 to 1.53$)$ & $0.74(0.54$ to 1.02$)$ & $0.90(0.71$ to 1.14$)$ & 1.00 & 0.29 \\
\hline All-cause mortality $(n=856)$ : & $(n=60)$ & $(n=139)$ & $(n=236)$ & $(n=421)$ & \\
\hline Age adjusted & 1.10 (0.84 to 1.45$)$ & $1.00(0.82$ to 1.21$)$ & $0.88(0.75$ to 1.04$)$ & 1.00 & 0.99 \\
\hline Multiple adjusted & 1.09 (0.83 to 1.45$)$ & $1.03(0.85$ to 1.26$)$ & $0.93(0.79$ to 1.09$)$ & 1.00 & 0.77 \\
\hline $\begin{array}{l}\text { Cardiovascular disease death } \\
(n=179) \text { : }\end{array}$ & $(n=21)$ & $(n=32)$ & $(n=43)$ & $(n=83)$ & \\
\hline Age adjusted & 1.77 (1.09 to 2.88$)$ & 1.07 (0.71 to 1.62$)$ & $0.78(0.54$ to 1.13$)$ & 1.00 & 0.18 \\
\hline Multiple adjusted & 1.68 (1.02 to 2.79$)$ & 1.18 (0.77 to 1.79$)$ & 0.87 (0.60 to 1.27$)$ & 1.00 & 0.13 \\
\hline $\begin{array}{l}\text { Non-cardiovascular disease } \\
\text { death }(n=677) \text { : }\end{array}$ & $(n=39)$ & $(n=107)$ & $(n=193)$ & $(n=338)$ & \\
\hline Age adjusted & 0.92 (0.66 to 1.28$)$ & $0.98(0.78$ to 1.22$)$ & 0.91 (0.76 to 1.09$)$ & 1.00 & 0.48 \\
\hline Multiple adjusted & 0.92 (0.65 to 1.29$)$ & $1.00(0.65$ to 1.25$)$ & $0.94(0.79$ to 1.13$)$ & 1.00 & 0.62 \\
\hline \multicolumn{6}{|c|}{$\begin{array}{l}\text { *Estimated with the Modification of Diet in Renal Disease Study equation. }{ }^{23} \\
\text { †Adjusted for age, systolic blood pressure, antihypertensive treatment, smoking, body mass index, alcohol consumption, exercise, total cholesterol, C } \\
\text { reactive protein, use of hormone replacement therapy, diabetes, and assigned treatments. } \\
\text { łP for trend across median values of the GFR categories. } \\
\text { §Defined as the first of any of non-fatal stroke, non-fatal myocardial infarction, coronary revascularisation procedure, or death from cardiovascular } \\
\text { cause. } \\
\text { शIncludes reports of bypass surgery or percutaneous coronary angioplasty. }\end{array}$} \\
\hline
\end{tabular}

(0.58 to 1.16$)$ for coronary revascularisation, $0.99(0.66$ to 1.47$)$ for stroke, $1.10(0.83$ to 1.46$)$ for all-cause mortality, 1.74 (1.05 to 2.89$)$ for cardiovascular mortality, and 0.92 (0.65 to 1.29$)$ for non-cardiovascular mortality.

Lastly, we did not find evidence that the lack of association between GFR and overall cardiovascular disease was modified by age ( $\mathrm{P}$ interaction $=0.19)$, body mass index $(\mathrm{P}$ interaction $=0.49)$, history of hypertension $(\mathrm{P}$ interaction $=0.14)$, smoking status $(\mathrm{P}$ interaction $=0.92)$, and total cholesterol concentration $(\mathrm{P}$ interaction $=0.65$ ). With regard to all-cause mortality, we found significant effect modification by history of hypertension $(\mathrm{P} \quad$ interaction $=0.02) \quad$ suggesting increased risk of death from any cause for women with a history of hypertension (hazard ratio 1.31 ( 0.92 to 1.86$)$ ). The association between GFR and all-cause mortality was not modified by age, body mass index, smoking status, or total cholesterol (all P interaction $\geq 0.1$ ).

\section{DISCUSSION}

In this large prospective cohort of mostly white women who were aged $\geq 45$ and free of cardiovascular disease and other major disease including symptomatic kidney disease at study entry, we did not observe an increased risk of any cardiovascular disease event or mortality for the more than 11000 women with GFR between 60 and $89 \mathrm{ml} / \mathrm{min} / 1.73 \mathrm{~m}^{2}$, data we believe both important and reassuring given recent suggestions of a link between renal impairment and incident cardiovascular disease. Our results further indicate that a GFR $<60 \mathrm{ml} / \mathrm{min} / 1.73 \mathrm{~m}^{2}$ seemed to be associated with increased risk of cardiovascular death but not with any other first cardiovascular event or non-cardiovascular mortality when compared with women with a GFR $\geq 90 \mathrm{ml} / \mathrm{min} / 1.73 \mathrm{~m}^{2}$. When we evaluated creatinine concentration rather than estimated GFR, the associations with cardiovascular disease and mortality were similar.

Comparison with other studies

Several studies have found increased risk of cardiovascular disease for individuals with impaired kidney function. ${ }^{10131426-28}$ However, most of these studies were of patients with existing cardiovascular disease or who were at high risk for cardiovascular disease or were limited to individuals aged 65 and above. ${ }^{26-28}$ Two 
Table 3| Hazard ratios (95\% confidence intervals) for cardiovascular events and mortality among 27939 participants in the Women's Health Study by blood creatinine concentration. Hazard ratios are adjusted for age and for multiple variables*

\begin{tabular}{|c|c|c|c|c|c|}
\hline \multirow[b]{2}{*}{ Event } & \multicolumn{4}{|c|}{ Creatinine concentration (centiles) $†$} & \multirow[b]{2}{*}{$P$ value for trend $f$} \\
\hline & $<50$ th $(n=14043)$ & $50-74$ th $(n=6900)$ & $75-94$ th $(n=5598)$ & $\geq 95$ th $(n=1398)$ & \\
\hline $\begin{array}{l}\text { Any cardiovascular event } \\
(n=1199) \S:\end{array}$ & $N=604$ & $\mathrm{~N}=275$ & $N=239$ & $N=81$ & \\
\hline Age adjusted & 1.00 & $0.90(0.78$ to 1.04$)$ & $0.91(0.78$ to 1.05$)$ & $1.14(0.90$ to 1.44$)$ & 0.95 \\
\hline Multiple adjusted & 1.00 & $0.92(0.80$ to 1.06$)$ & $0.89(0.77$ to 1.04$)$ & $0.99(0.78$ to 1.26$)$ & 0.41 \\
\hline Myocardial infarction $(n=313)$ : & $N=146$ & $N=81$ & $N=69$ & $\mathrm{~N}=17$ & \\
\hline Age adjusted & 1.00 & $1.10(0.84$ to 1.45$)$ & $1.08(0.81$ to 1.44$)$ & 0.99 (0.60 to 1.64$)$ & 0.76 \\
\hline Multiple adjusted & 1.00 & $1.13(0.86$ to 1.49$)$ & $1.06(0.79$ to 1.42$)$ & $0.86(0.51$ to 1.43$)$ & 0.83 \\
\hline $\begin{array}{l}\text { Coronary revascularisation } \\
(n=675) \Uparrow:\end{array}$ & $N=342$ & $N=161$ & $N=134$ & $N=38$ & \\
\hline Age adjusted & 1.00 & $0.94(0.78$ to 1.13$)$ & $0.91(0.75$ to 1.12$)$ & 0.97 (0.69 to 1.35$)$ & 0.51 \\
\hline Multiple adjusted & 1.00 & $0.95(0.79$ to 1.15$)$ & 0.87 (0.71 to 1.07$)$ & $0.82(0.58$ to 1.16$)$ & 0.13 \\
\hline Stroke $(n=389)$ : & $N=206$ & $\mathrm{~N}=80$ & $N=74$ & $N=29$ & \\
\hline Age adjusted & 1.00 & 0.77 (0.59 to 0.99) & $0.81(0.62$ to 1.05$)$ & 1.17 (0.79 to 1.72$)$ & 0.73 \\
\hline Multiple adjusted & 1.00 & $0.78(0.60$ to 1.01$)$ & $0.80(0.61$ to 1.04$)$ & 0.99 (0.66 to 1.47$)$ & 0.34 \\
\hline All-cause mortality ( $n=856)$ : & $N=433$ & $\mathrm{~N}=179$ & $N=186$ & $N=58$ & \\
\hline Age adjusted & 1.00 & 0.82 (0.69 to 0.97$)$ & $0.97(0.82$ to 1.15$)$ & 1.13 (0.86 to 1.49$)$ & 0.74 \\
\hline Multiple adjusted & 1.00 & $0.85(0.71$ to 1.01$)$ & $1.01(0.85$ to 1.20$)$ & $1.10(0.83$ to 1.46$)$ & 0.67 \\
\hline $\begin{array}{l}\text { Cardiovascular disease death } \\
(\mathrm{n}=179) \text { : }\end{array}$ & $N=84$ & $N=34$ & $N=41$ & $N=20$ & \\
\hline Age adjusted & 1.00 & 0.80 (0.54 to 1.19$)$ & $1.07(0.74$ to 1.56$)$ & 1.91 (1.17 to 3.12$)$ & 0.03 \\
\hline Multiple adjusted & 1.00 & 0.87 (0.58 to 1.30$)$ & $1.18(0.80$ to 1.72$)$ & 1.74 (1.05 to 2.89$)$ & 0.04 \\
\hline $\begin{array}{l}\text { Non-cardiovascular disease } \\
\text { death }(n=677) \text { : }\end{array}$ & $N=349$ & $N=145$ & $N=145$ & $N=38$ & \\
\hline Age adjusted & 1.00 & $0.82(0.68$ to 1.00$)$ & $0.95(0.78$ to 1.15$)$ & $0.93(0.66$ to 1.30$)$ & 0.45 \\
\hline Multiple adjusted & 1.00 & 0.84 (0.69 to 1.03$)$ & 0.97 (0.80 to 1.18$)$ & $0.92(0.65$ to 1.29$)$ & 0.51 \\
\hline
\end{tabular}

*Adjusted for age, systolic blood pressure, antihypertensive treatment, smoking, body mass index, alcohol consumption, exercise, total cholesterol, $\mathrm{C}$ reactive protein, use of hormone replacement therapy, diabetes, and assigned treatments.

†Equivalent to $\leq 63 \mu \mathrm{mol} / \mathrm{l}, 64-70 \mu \mathrm{mol} / \mathrm{l}, 71-88 \mu \mathrm{mol} / \mathrm{l}, \geq 89 \mu \mathrm{mol} / \mathrm{l}$.

$\ddagger P$ for trend across median values of the creatinine categories.

$\S$ Defined as the first of any of non-fatal stroke, non-fatal myocardial infarction, coronary revascularisation procedure, or death from cardiovascular cause.

IIncludes reports of bypass surgery or percutaneous coronary angioplasty.

studies were published from the population based, prospective Cardiovascular Health Study, which included individuals aged 65 and above. The first evaluated the association between creatinine concentration and cardiovascular outcomes. ${ }^{27}$ Results indicated steadily increasing risk of all-cause mortality, cardiovascular mortality, non-cardiovascular mortality, overall cardiovascular disease, and congestive heart failure with increasing levels of creatinine. The second study assessed several measures of kidney function - including creatinine levels, estimated GFR, and cystatin C concentration-all of which were associated with increased risk of all-cause mortality, cardiovascular mortality, myocardial infarction, and stroke. ${ }^{26} \mathrm{How}^{-}$ ever, participants in the Cardiovascular Health Study were older and were considerably sicker than participants in the Women's Health Study and included patients with existing cardiovascular disease, congestive heart failure, and cancer, which may explain the different findings compared with our study with regard to non-fatal cardiovascular disease.

In a large, community based study using administrative data, impaired GFR was strongly associated with all-cause mortality, cardiovascular events, and rates of hospitalisation. ${ }^{13}$ However, the evaluated GFR ranges were much lower than in our study, and individuals with prior stroke, transient ischaemic attacks, peripheral artery disease, and chronic heart failure were included. Compared with participants with a GFR $\geq 60 \mathrm{ml} / \mathrm{min} / 1.73 \mathrm{~m}^{2}$, participants with a GFR $<15 \mathrm{ml} / \mathrm{min} / 1.73 \mathrm{~m}^{2}$ had adjusted hazard ratios ranging from 3.1 (95\% confidence interval 3.0 to 3.3) for any hospitalisation to 5.9 (5.4 to 6.5 ) for death from any cause. Another study showed similar results indicating that patients with prior myocardial infarction and severe renal dysfunction $\left(\mathrm{GFR}<45 \mathrm{ml} / \mathrm{min} / 1.73 \mathrm{~m}^{2}\right.$ ) had increased risk for recurrent coronary events. ${ }^{29}$ However, even in this high risk population, risks were not increased among those with less severe levels of kidney impairment (GFR 60-74 ml/min/1.73 $\mathrm{m}^{2}$ ). When we further subdivided our low GRF group to values of $<40 \mathrm{ml} / \mathrm{min} / 1.73 \mathrm{~m}^{2}$, we observed increased risk of all-cause mortality, which was driven by cardiovascular mortality. However, we only had 67 women in this category, which limits any interpretation of these findings.

Further, in a cohort of 37153 individuals who were screened in the National Kidney Foundation's Kidney Early Evaluation Program and who were followed for a median of 16 months, three measures of chronic 
kidney disease (GFR $<60 \mathrm{ml} / \mathrm{min} / 1.73 \mathrm{~m}^{2}$, microalbuminuria $>30 \mathrm{mg} / \mathrm{l}$, and anaemia) were associated with increased risk of death. Further, participants who had all three factors present had the lowest survival. ${ }^{30}$ In the Women's Health Study no information on microalbuminuria or anaemia was available.

With regard to stroke subtypes, findings from the Rotterdam Study indicated increased risk of haemorrhagic stroke for individuals with decreased kidney function. ${ }^{31}$ Compared with participants with the highest quarter of GFR values, those with the lowest values had a hazard ratio (adjusted for age and sex) of 4.10 (1.25 to 13.42). Our data do not indicate an association between kidney function and haemorrhagic stroke, but the low number of such events in our study $(\mathrm{n}=73)$ and in the Rotterdam Study $(\mathrm{n}=44)$ means the results should be interpreted cautiously. Similar to our data, there was no association with ischaemic stroke in the data from the Netherlands.

The overall epidemiological evidence associating impaired kidney function with risk of cardiovascular disease and mortality suggests that individuals with a GFR $<60 \mathrm{ml} / \mathrm{min} / 1.73 \mathrm{~m}^{2}$ are at increased risk of cardiovascular death, and the risk steadily increases with decreasing GFR values below 60 . The increased risk of myocardial infarction and stroke as well as noncardiovascular mortality may be limited to individuals with existing cardiovascular disease or who are at high risk for cardiovascular disease events. In addition, patients with GFR $<30 \mathrm{ml} / \mathrm{min} / 1.73 \mathrm{~m}^{2}$ may be at increased risk for all cardiovascular disease events and all-cause mortality.

The association between kidney function and cardiovascular disease is complex. It has been shown that risk factors for cardiovascular disease also predict impaired kidney function. For example, in the Framingham Heart Study, body mass index, smoking, and diabetes are predictors of impaired kidney function. ${ }^{7}$ Furthermore, data from the Physicians' Health Study indicated that higher cholesterol levels, ${ }^{6}$ high body mass index, ${ }^{9}$ and abstaining from drinking alcohol $^{8}$ were risk factors for chronic kidney disease. Thus, impaired kidney function may be a marker for individuals with a more unfavourable cardiovascular disease risk profile and not a biological risk factor per se for subsequent cardiovascular disease.

\section{Strengths and limitations of study}

Our study has several strengths, including the large number of participants and outcome events, high participation rate and long follow-up, confirmed cardiovascular disease events after medical record review, the homogeneity of the study (which may reduce bias), and available information on a large number of potential confounding factors.

Several limitations should be considered when interpreting our results. First, creatinine concentration was measured only once, and thus change of creatinine over time could not be evaluated.

Second, we used the Modification of Diet in Renal Disease Study equation to estimate GFR, which may result in misclassification of kidney function. However, the equation predicts GFR well, and its use is recommend by the National Kidney Foundation. ${ }^{24}$ In addition, when we used creatinine categories or the Cockcroft-Gault equation ${ }^{32}$ (data not shown) to estimate kidney function, we found a similar pattern of association between impaired kidney function and cardiovascular disease events. We had no other measures of impaired kidney function available, such as microalbuminuria or cystatin C. Cystatin C may be a better marker of chronic kidney disease than creatinine and may be a better predictor for cardiovascular disease. $^{28}$

Third, despite adjustment for a large number of potential confounders, residual and unmeasurable confounding may be present since our data are observational.

Fourth, although the overall number of outcome events was large, we had limited numbers of individual events in each of the GFR subgroups, so our findings should be interpreted cautiously.

Lastly, all participants were female health professionals and most of them white, which may limit generalisability to other populations. Indeed, data suggest that the association between impaired kidney function and cardiovascular disease or mortality is more apparent in black people ${ }^{14}$ and men. ${ }^{18}$

\section{Conclusions}

Data from this large prospective cohort of women without prior cardiovascular disease or other major disease at study entry do not indicate an association between mild to moderate kidney impairment and increased risk of cardiovascular disease or mortality. Impaired kidney function (GFR $<60 \mathrm{ml} / \mathrm{min}$ / $\left.1.73 \mathrm{~m}^{2}\right)$ seemed to be associated with an increased risk of cardiovascular disease death but not other cardiovascular or mortality outcomes, a finding that deserves further investigations.

We thank the participants in the Women's Health Study for their outstanding commitment and cooperation, the Women's Health Study staff for their expert and unfailing assistance, and Eunjung Kim for programming assistance.

Contributions: TK conceived and designed the study, analysed the data, and drafted the manuscript. JEB and PMR were responsible for data acquisition. All authors interpreted the data, critically revised the draft, and gave final approval of the version to be published. TK is guarantor of the study.

Funding: The Women's Health Study is supported by grants and from the National Heart, Lung, and Blood Institute (HL-043851 and HL-080467), and the National Cancer Institute (CA-047988). The research for this work was supported by grants from the Donald W Reynolds Foundation, the Leducq Foundation, and the Doris Duke Charitable Foundation. The funding sources played no role in the study design; in the collection, analysis, and interpretation of the data; in the writing of the manuscript; or in the decision to submit the manuscript for publication.

Competing interests: None declared, but we report a full disclosure for the past five years. TK has received research funding from Merck, McNeil Consumer \& Specialty Pharmaceuticals, the National Institutes of Health, and Wyeth Consumer Healthcare; is a consultant to i3 Drug Safety and World Health Information Science Consultants, LLC; and received honorariums from Genzyme, Merck, and Pfizer for lectures. PEd] has received research funding from the Dutch Kidney Foundation. NRC has received research funding and support from the National Institutes of Health and from Roche Molecular Systems. JEB has received research funding and support from Dow Corning Corporation and the National 


\section{WHAT IS ALREADY KNOWN ON THIS TOPIC}

Impaired kidney function has been associated with increased risk of cardiovascular disease and mortality among patients with existing kidney disease or existing cardiovascular disease

\section{WHAT THIS STUDY ADDS}

This large prospective study of women free of vascular disease or symptomatic kidney disease at baseline indicates no association between kidney function and major cardiovascular disease or all-cause mortality

Impaired kidney function (glomerular filtration rate $<60 \mathrm{ml} / \mathrm{min} / 1.73 \mathrm{~m}^{2}$ ) seemed to be associated with an increased risk of cardiovascular disease death but was not associated with any other cardiovascular or mortality outcome
Institutes of Health; research support from Bayer Heath Care and the Natural Source Vitamin E Association; honorariums from Bayer for lectures; and serves on an external scientific advisory committee for a study by Procter \& Gamble. PMR has received research funding and support from the American Heart Association, AstraZeneca, Bayer, Bristol-Myers Squibb, Dade-Behring, Doris Duke Charitable Foundation, James and Polly Annenberg La Vea Charitable Trusts, Leducq Foundation, the National Institutes of Health, Novartis, Merck, Donald W Reynolds Foundation, Pharmacia, Roche, Sanofi/Aventis, and Variagenics; is listed as coinventor on patents held by Brigham and Women's Hospital on the use of inflammatory biomarkers in cardiovascular disease; and has served as consultant to AstraZeneca, Dade-Behring, Interleukin Genetics, Isis Pharmaceuticals, Sanofi/Aventis, and Schering-Plough,

1 US Renal Data System (USRDS). USRDS 2008 annual data report: atlas of end-stage renal disease in the United States. Bethesda, MD: National Institutes of Health, National Institute of Diabetes and Digestive and Kidney Diseases, 2008.

2 Rosamond W, Flegal K, Friday G, Furie K, Go A, Greenlund K, et al. Heart disease and stroke statistics-2007 update: a report from the American Heart Association Statistics Committee and Stroke Statistics Subcommittee. Circulation 2007;115:e69-171.

3 Sarnak MJ, Levey AS. Cardiovascular disease and chronic renal disease: a new paradigm. Am J Kidney Dis 2000;35(4 suppl 1):117-31.

4 Sarnak MJ, Levey AS, Schoolwerth AC, Coresh J, Culleton B, Hamm LL, et al. Kidney disease as a risk factor for development of cardiovascular disease: a statement from the American Heart Association Councils on Kidney in Cardiovascular Disease, High Blood Pressure Research, Clinical Cardiology, and Epidemiology and Prevention. Circulation 2003;108:2154-69.

5 Elsayed EF, Tighiouart H, Griffith J, Kurth T, Levey AS, Salem D, et al. Cardiovascular disease and subsequent kidney disease. Arch Intern Med 2007:167(11):1130-6.

6 Schaeffner ES, Kurth T, Curhan GC, Glynn RJ, Rexrode KM, Baigent C, et al. Cholesterol and the risk of renal dysfunction in apparently healthy men. / Am Soc Nephrol 2003;14:2084-91.

7 Fox CS, Larson MG, Leip EP, Culleton B, Wilson PW, Levy D. Predictors of new-onset kidney disease in a community-based population. JAMA 2004;291:844-50.

8 Schaeffner ES, Kurth T, de Jong PE, Glynn RJ, Buring JE, Gaziano JM. Alcohol consumption and the risk of renal dysfunction in apparently healthy men. Arch Intern Med 2005;165:1048-53.

9 Gelber RP, Kurth T, Kausz AT, Manson JE, Buring JE, Levey AS, et al. Association between body mass index and chronic kidney disease in apparently healthy men. Am J Kidney Dis 2005;46:871-80.

10 Weiner DE, Tighiouart H, Stark PC, Amin MG, MacLeod B, Griffith JL, et al. Kidney disease as a risk factor for recurrent cardiovascular disease and mortality. Am J Kidney Dis 2004;44:198-206.

11 Beattie JN, Soman SS, Sandberg KR, Yee J, Borzak S, Garg M, et al. Determinants of mortality after myocardial infarction in patients with advanced renal dysfunction. Am J Kidney Dis 2001;37:1191-200.
12 Shlipak MG, Heidenreich PA, Noguchi H, Chertow GM, Browner WS, McClellan MB. Association of renal insufficiency with treatment and outcomes after myocardial infarction in elderly patients. Ann Intern Med 2002;137:555-62.

13 Go AS, Chertow GM, Fan D, McCulloch CE, Hsu CY. Chronic kidney disease and the risks of death, cardiovascular events, and hospitalization. N Engl J Med 2004:351:1296-305.

14 Weiner DE, Tighiouart H, Amin MG, Stark PC, MacLeod B, Griffith JL, et al. Chronic kidney disease as a risk factor for cardiovascular disease and all-cause mortality: a pooled analysis of communitybased studies. J Am Soc Nephrol 2004;15:1307-15.

15 Shlipak MG, Simon JA, Grady D, Lin F, Wenger NK, Furberg CD. Rena insufficiency and cardiovascular events in postmenopausal women with coronary heart disease. J Am Coll Cardiol 2001;38:705-11.

16 Muntner P, He J, Hamm L, Loria C, Whelton PK. Renal insufficiency and subsequent death resulting from cardiovascular disease in the United States. / Am Soc Nephrol 2002;13:745-53.

17 Garg AX, Clark WF, Haynes RB, House AA. Moderate renal insufficiency and the risk of cardiovascular mortality: results from the NHANES I. Kidney Int 2002;61:1486-94.

18 Culleton BF, Larson MG, Wilson PW, Evans JC, Parfrey PS, Levy D. Cardiovascular disease and mortality in a community-based cohort with mild renal insufficiency. Kidney Int 1999;56:2214-9.

19 Henry RM, Kostense PJ, Bos G, Dekker IM, Nijpels G, Heine Rl, et al. Mild renal insufficiency is associated with increased cardiovascular mortality: The Hoorn Study. Kidney Int 2002;62:1402-7.

20 Ridker PM, Cook NR, Lee IM, Gordon D, Gaziano IM, Manson JE, et al. A randomized trial of low-dose aspirin in the primary prevention of cardiovascular disease in women. $N$ Engl / Med 2005;352:1293-304.

21 Cook NR, Lee IM, Gaziano IM, Gordon D, Ridker PM, Manson JE, et al. Low-dose aspirin in the primary prevention of cancer: the Women's Health Study: a randomized controlled trial. JAMA 2005;294:47-55.

22 Lee IM, Cook NR, Gaziano JM, Gordon D, Ridker PM, Manson JE, et al. Vitamin $\mathrm{E}$ in the primary prevention of cardiovascular disease and cancer: the Women's Health Study: a randomized controlled trial. JAMA 2005;294:56-65.

23 Levey AS, Bosch IP, Lewis IB, Greene T, Rogers N, Roth D. A more accurate method to estimate glomerular filtration rate from serum creatinine: a new prediction equation. Modification of Diet in Renal Disease Study Group. Ann Intern Med 1999;130:461-70.

24 Levey AS, Coresh J, Balk E, Kausz AT, Levin A, Steffes MW, et al. National Kidney Foundation practice guidelines for chronic kidney disease: evaluation, classification, and stratification. Ann Intern Med 2003:139:137-47.

25 Atiya M, Kurth T, Berger K, Buring JE, Kase CS. Interobserver agreement in the classification of stroke in the Women's Health Study. Stroke 2003;34:565-7.

26 Shlipak MG, Fried LF, Cushman M, Manolio TA, Peterson D, Stehman-Breen C, et al. Cardiovascular mortality risk in chronic kidney disease: comparison of traditional and novel risk factors. JAMA 2005:293:1737-45.

27 Fried LF, Shlipak MG, Crump C, Bleyer AJ, Gottdiener JS, Kronmal RA, et al. Renal insufficiency as a predictor of cardiovascular outcomes and mortality in elderly individuals. / Am Coll Cardiol 2003:41:1364-72.

28 Shlipak MG, Sarnak MJ, Katz R, Fried LF, Seliger SL, Newman AB, et al. Cystatin $C$ and the risk of death and cardiovascular events among elderly persons. N Engl/ Med 2005;352:2049-60.

29 Tokmakova MP, Skali H, Kenchaiah S, Braunwald E, Rouleau JL, Packer M, et al. Chronic kidney disease, cardiovascular risk, and response to angiotensin-converting enzyme inhibition after myocardial infarction: the Survival And Ventricular Enlargement (SAVE) study. Circulation 2004;110:3667-73.

30 McCullough PA, Jurkovitz CT, Pergola PE, McGill JB, Brown WW, Collins AJ, et al. Independent components of chronic kidney disease as a cardiovascular risk state: results from the Kidney Early Evaluation Program (KEEP). Arch Intern Med 2007;167:1122-9.

31 Bos MJ, Koudstaal PJ, Hofman A, Breteler MM. Decreased glomerular filtration rate is a risk factor for hemorrhagic but not for ischemic stroke: the Rotterdam Study. Stroke 2007;38:3127-32.

32 Cockroft DW, Gault MH. Prediction of creatinine clearance from serum creatinine. Nephron 1976;16:31-41.

Accepted: 13 February 2009 